\title{
Sowing seeds for the future: the need for establishing protocols for the study of seed dormancy
}

\author{
Fernando Augusto Oliveira Silveira ${ }^{1,2}$
}

Submitted: 31 March, 2012. Accepted: 16 December, 2012

\begin{abstract}
Seed dormancy is a widely misunderstood plant trait. In several research areas, a lack of germination is wrongly assumed to result from seed dormancy. In an attempt to standardize seed dormancy research and improve communication among seed scientists, a straightforward protocol to address the occurrence and causes of seed dormancy is provided. Standardizing communication is not just a theoretical exercise but also has practical implications in agriculture and conservation. Standardization will make studies comparable and hence we will have a deeper understanding of the physiology, ecology and evolution of seed dormancy. A better understanding of the various aspects of seed dormancy will lead to greater appreciation of the biogeographical and phylogenetic distribution of seed dormancy among our flora.
\end{abstract}

Key words: Dormancy classification system, viability, embryoless seeds, lack of germination

"Not specifying the kind of seed dormancy in studies focusing on this subject may be somewhat analogous to not including the Latin name of the study organism in scientific articles"

- Jerry M. Baskin and Carol C. Baskin (2004)

\section{Introduction}

The understanding of seed dormancy is at the core of seed biology. However, because seed dormancy is a widely misunderstood seed trait (Hilhorst 2011; Thompson \& Ooi 2010), clear definitions are needed in order to improve scientific communication. The virtues and shortcomings of each among the numerous definitions of seed dormancy have been discussed elsewhere (Vleeshouwers et al. 1995; Benech-Arnold et al. 2000; Baskin \& Baskin 2004; Cardoso 2004; Finch-Savage \& Leubner-Metzger 2006; Finkelstein et al. 2008; Linkies et al. 2010; Hilhorst 2011) and here, some methodological issues and misinterpretations regarding the study of seed dormancy are addressed. In this paper, I adopt the terminology put forward by Hilhorst (2011), who defines dormancy as the absence of germination of a viable seed under conditions that are favourable to its germination. The internationally accepted dormancy classification system by Baskin \& Baskin (2004) is followed here. This system encompasses five dormancy classes: physical, combinational, physiological, morphological and morphophysiological.
Despite the great importance for the correct assignment of seed dormancy classes (see examples in Baskin \& Baskin 2005), poor experimental design and data misinterpretation prevent us from distinguishing between dormant/nondormant states and among seed dormancy kinds. In this paper, attention is given to a phenomenon called "dormancism", defined as a trend to assign dormancy to all seeds that do not germinate in experimental trials. My main criticism is that the absence of germination is inappropriately assumed to be the result of dormancy. Hilhorst (2011) considers it inaccurate to use the total germination in a population after a defined period of time as the sole criterion in dormancy essays. This misunderstanding is repeated in disciplines spanning many levels of biological organisation including plant physiology, ecology and evolution, as well as in studies addressing the effects of the environmental control of germination, the effects of vertebrate gut passage on germination, intraspecific levels of dormancy, and other topics.

Inaccuracies and mistakes in seed biology may obstruct effective communication among seed scientists. Incorrect data interpretation is also common in seed biology and may arise from poor communication. In the paper "Mistakes in

\footnotetext{
${ }^{1}$ Universidade Federal de Minas Gerais, Instituto de Ciências Biológicas, Departamento de Botânica, Belo Horizonte, Minas Gerais, Brazil

${ }^{2}$ Author for correspondence: faosilveira@icb.ufmg.br
} 
germination ecology and how to avoid them", Baskin et al. (2006) argue that without adequate methodology, no conclusion on seed dormancy can be accurately drawn. Here, a straightforward protocol for improvement of seed dormancy trials is provided with the expectation that increased recognition of factors controlling seed dormancy and germination will have a direct and positive impact on the quality of future studies of the Brazilian flora. The proffered guidelines are expected to help clarifying how standardized protocols can improve data quality. The reader is highly recommended to refer to Baskin \& Baskin (2004), Baskin et al. (2006) and Hilhorst (2011) for further information.

\section{Diagnosing the problems in experi- mental design and in data interpre- tation}

Methodological problems concerning statistical matters will not be discussed here. The reader is referred to Ranal \& Santana (2006) and McNair et al. (2012) for excellent essays regarding these issues. Molecular methods are deeply increasing our understanding of seed dormancy (FinchSavage \& Footit 2012), but they will also not be discussed here. Rather, this paper aims to discuss how the lack of standardized research protocols can lead to misunderstandings in data interpretation and how we can learn from those mistakes in order to avoid them in the future.

\section{On the factors that cause low germinability}

There are a variety of reasons why seeds may not germinate, and seed dormancy is only one among them (Hilhorst 2011; Fig. 1). First, unsuitable conditions for germination may prevent seeds from germinating. Therefore, testing germination under a wide range of physical conditions is especially recommended (see Finch-Savage \& Leubner-Metzger 2006 for a discussion on light and dormancy). Second, many species have high proportions of embryoless seeds, including Melastomataceae (Simão et al. 2007; Silveira et al., 2012), Asteraceae (Velten \& Garcia 2005; Galastri \& Oliveira 2010; Le Stradic 2012) and Poaceae (Le Stradic 2012). The proportion of embryoless seeds can be over 95\% (Gupta \& Murty 1986). The embryoless seeds of many species are externally indistinguishable from seeds that contain embryos, and failure to differentiate between the two may dramatically affect the outcome of germination experiments. Finally, seeds may fail to germinate because embryos are not viable. These three factors converge to produce exactly the same response as if seeds were dormant: the absence of germination.

Though it may be appealing to assign dormancy to non-germinants, no assumption of dormancy can be made without conducting viability tests. Hilhorst (2011) is clear on that point. The author mentions that it is evidently quite important to discriminate between dead seeds and non-germinating dormant seeds. The critical point here is that the germination responses of non-germinant seeds that are dead (or embryoless) are the same as those presented by dormant seeds. Therefore, we are unable to correctly determine whether non-germinant seeds are dormant unless viability tests are conducted.

\section{The classification system of dormancy should be explicitly mentioned}

Given the several dormancy classification systems, and the multitude of backgrounds among seed scientists (plant ecologists, plant molecular biologists, agronomists, plant physiologists, forest engineers, and others), it is understandable that there are academic/historical preferences for the many available dormancy classification systems. However, the omission of the adopted dormancy classification system hampers communication among scientists and comparative studies across ecological levels. Therefore, it is extremely important to report which seed classification system was followed.

\section{The kind of seed dormancy should be determined prior to applying methods to break it}

It is not enough to state which classification system was followed if the kind of dormancy is not determined. Omitting the kind of seed dormancy would seem to be analogous to a publication on photosynthesis of a plant that does not indicate the carbon pathway (Baskin \& Baskin 2004). By misinterpreting the class of seed dormancy, researchers may fail to apply the correct methods to overcome dormancy. For instance, increases in germinability following chemical or mechanical scarification are sometimes regarded as evidence that seeds have physical dormancy. However, to confirm physical dormancy, one should be able to demonstrate whether seeds or fruits are impermeable to water (Baskin et al. 2006). Even if the aim is not to apply methods for dormancy breaking, it is recommended that researchers disclose the kind of seed dormancy because it furthers understanding of the theoretical and practical aspects of seed dormancy.

\section{Methods to overcome dormancy should be directed towards the specific kind of dormancy}

In medicine, one should determine the disease before prescribing a drug. Why should it be different in seed biology? Applying methods to overcome dormancy without knowing the mechanisms causing seed dormancy is a shot in the dark. Once the kind of dormancy has been properly determined, treatments for dormancy breaking can be efficiently employed. As a general rule, different classes of dormancy require different methods for dormancy breaking (Hilhorst 2011). Who wants to waste money and time using plant growth regulators to overcome physical dormancy? 


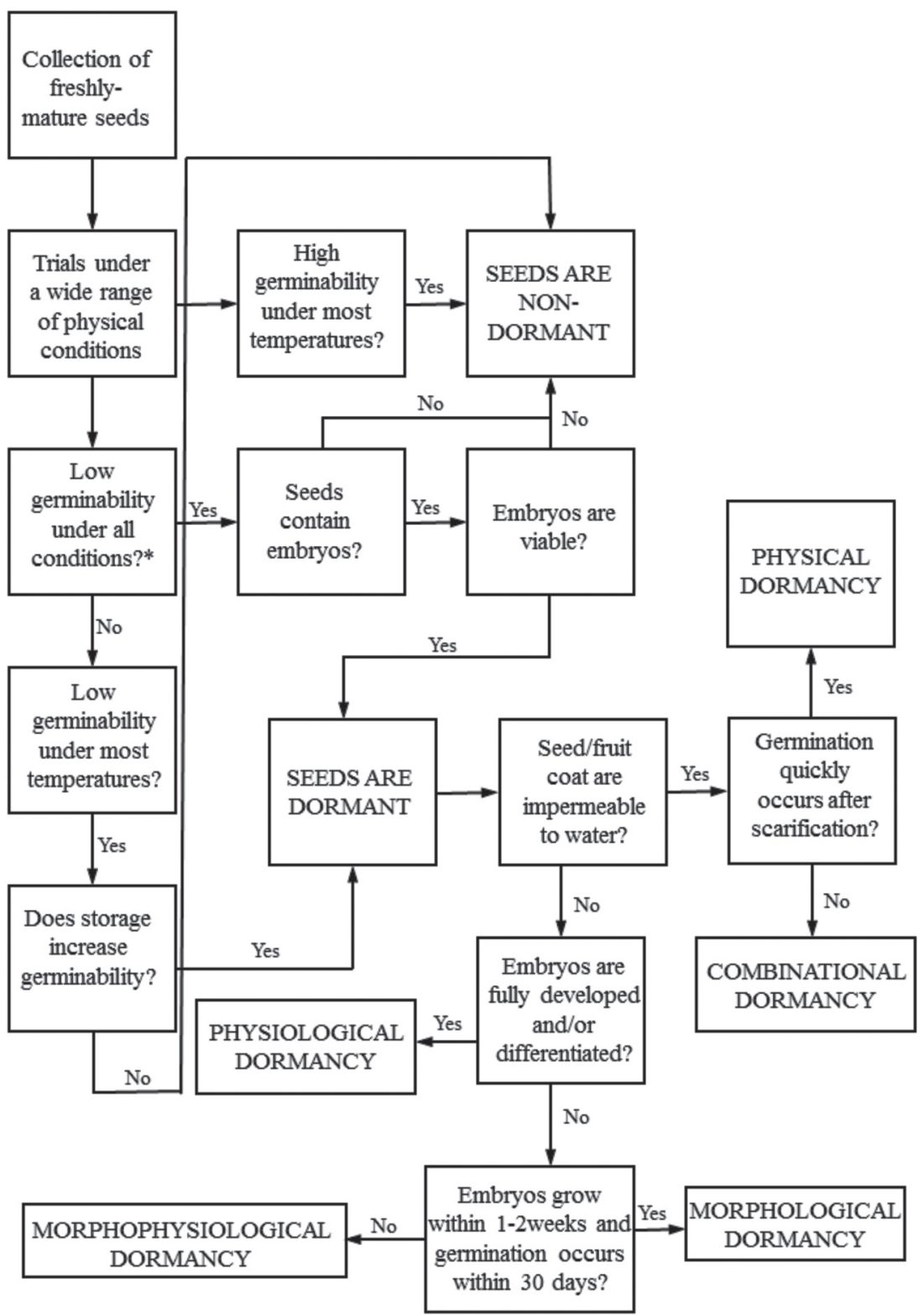

Figure 1. A conceptual framework for the development of standardized protocols in seed dormancy studies. Seed dormancy classification follows Baskin \& Baskin (2004). Also refer to Baskin \& Baskin (2005) and Hilhorst (2011) for further information.

${ }^{*}$ Conditions refer mainly to temperature, but germination cues may differ among species (Thompson \& Ooi 2010).

\section{Researchers should discriminate between germination promoters and dormancy-breaking chemicals}

There is a crucial, though controversial, distinction between dormancy alleviation and germination stimulation. Failure to discriminate between them can have both theoretical and practical consequences (Benech-Arnold et al. 2000; Thompson \& Ooi 2010). Misunderstandings may arise because a given factor may control both dormancy and germination. A germination cue is a change in the environment that aligns that environment with the germination requirements of the seed, whereas dormancy breaking is a change in the seed that determines what those requirements are (Thompson \& Ooi 2010). Therefore, light, smoke, nitrate and diurnal temperature alternations do not break dormancy but rather stimulate germination (but see Finch-Savage \& Footit 2012). This point is critical to enable us to understand how seed dormancy is broken (and how germination is stimulated) under field conditions (BenechArnold et al. 2000; Baskin et al. 2006). 


\section{Astep-by-step protocol for improving the quality of seed dormancy studies}

The guidelines provided below are insufficient to cover all aspects of seed dormancy research (see additional examples in Brasil 2009 and Hilhorst 2011). Standardizing seed dormancy research deserves a much longer and detailed discussion spanning terminology, experimental design, seed collection and storage, pre-germination treatments, statistical analyses and data reporting. Several steps are not within the scope of this essay and will not be discussed.

\section{Seed collection and germination experiments}

To correctly determine primary dormancy, which occurs in seeds that are released from the parent plant in a dormant state (Benech-Arnold et al. 2000), seeds must be collected at maturity. By collecting seeds in a pre-maturation state, researchers may be dealing with immature, embryoless seeds (Simão et al. 2007). In addition, the use of fresh seeds ensures reliable data for inference of dormancy at maturity (Baskin et al. 2006). Therefore, reporting the interval between seed collection and germination experiments, as well as the storage conditions, is vital to isolating other mechanisms that may create biased information. Correlated processes affecting germination responses include post-maturation seed deterioration and secondary dormancy induction, which can operate simultaneously or independently.

Seed viability must be assessed by means of seed dissection, viability tests or both. Seed dissection is particularly important for many small-sized seeds, in which viability tests may be difficult. The most common viability test is the tetrazolium test (Delouche et al. 1962; Piña-Rodrigues et al. 2004; Brasil 2009). If the seeds are not viable, the percentage of viable seeds should be reported, and germination percentages should be calculated on the basis of the number of viable seeds present at the start of the experiment (Baskin et al. 2006). Seeds must be set to germinate under a wide range of physical conditions, including both light and dark conditions (Fig. 1). As for tropical species, temperature conditions may range from $10^{\circ} \mathrm{C}$ to $35^{\circ} \mathrm{C}$ or even $40^{\circ} \mathrm{C}$. A deeper discussion on how long germination monitoring should be carried out is avoided here, but the suggested germination length for native species is a minimum of four weeks. Germination studies have multiple objectives, and the length of the experiment depends on specific goals targeted by the researchers. More importantly than the length of experimental trials, all tested conditions should allow the same period of time for germination (Baskin et al. 2006).

It should be clear that if large proportions of fresh seeds germinate within a short period of time, the seeds are not dormant. If viable seeds do not germinate under optimum conditions, seeds are regarded as dormant and the next step is to determine the dormancy kind (Fig. 1).

\section{Determining the kind of seed dormancy}

After determining that seeds are dormant, the next step is to identify the kind of seed dormancy. The dichotomous key devised by Baskin \& Baskin (2005) provides some essential information about the causes(s) of dormancy in each of the five classes (see Fig. 1). Physical dormancy implies that the seed/fruit coat is water impermeable. To determine if diaspores are water impermeable, they should be weighed before and after a period of incubation on a wet substrate or of soaking in tap water (Baskin et al. 2006). Periods of incubation may range from $8 \mathrm{~h}$ to $72 \mathrm{~h}$. Appropriate statistics must be run to determine whether there are significant differences between the seed mass of dried and soaked seeds (Silveira et al. 2012; Le Stradic 2012). The finding of seed/ fruit coat permeability supports the notion of physical or combinational dormancy and the use of scarification can distinguish between them (Fig. 1).

In the case of water permeable seed/fruit coats, an examination of embryo morphology is required (Fig. 1). The easiest way to examine embryos is to dissect seeds under a stereomicroscope (Silva et al. 2007; Le Stradic 2012). Detailed descriptions of embryo anatomy may prove helpful but are not strictly needed. To further assess details on embryo anatomy, routine anatomical procedures can be carried out (see Silveira et al. 2012 and references therein), but simple seed dissection procedures for evaluating embryo growth (Silva et al. 2007) or to confirm that seeds have fully developed/differentiated embryos are sufficient for assigning morphological or morphophysiological dormancy (Fig. 1). If seed coats are permeable, embryos are fully developed and there is rapid germination, the seeds are physiologically dormant (Fig. 1).

\section{Reporting data}

Fragmented information on basic data reporting prevents the validation of quality tests for native species seeds (Santana et al. 2012). Missing information in published studies may also hamper important meta-analysis and global appraisals of seed dormancy. For example, how can we determine the proportion of species with seed dormancy in each of the Brazilian biomes if the authors do not provide the exact location of seed collection? A number of factors can account for variation in germination, and, to make a better assessment of the role of each of these factors, researchers are encouraged to report the following in their papers (no suggestions regarding statistical issues are made here). With regards to the seed collection stage, I suggest providing a detailed description of the study site, including geographic coordinates, as well as details regarding climate, soil, vegetation, the date of seed collection, the number of diaspores/plant and the number of individuals sampled. For the germination trials, I suggest reporting at least the interval between seed collection and germination tests; the conditions under which the seeds where stored (if any); the results of seed dissection and viability tests; 
the specific physical conditions under which experiments were run, the criteria for germination and the length of the experiment.

\section{Concluding remarks}

Brazil is a megadiverse country comprising biomes that are structurally and functionally complex. The country harbours the highest plant diversity in the world (Forzza et al. 2012), and we have a unique opportunity to unravel long-standing questions regarding seed dormancy using our flora as a study model. Therefore, standardizing communication among seed scientists is paramount to a deeper understanding on the phylogenetic and biogeographic distribution of seed dormancy. Measuring seed dormancy is indeed a challenging task (Finch-Savage \& LeubnerMetzger 2006), but researchers must keep in mind that a multitude of correlated processes may affect the outcome of germination experiments. It is important to recognize that the absence of germination is not a surrogate for seed dormancy. By assigning dormancy to all non-germinant seeds we may not only be making a mistake but may also be missing a great opportunity to unravel other interesting events that determine seed fate.

When investigating seed dormancy, researchers should bear in mind the ideas that dormancy is not an all-ornothing trait and that the degree of seed dormancy varies at several scales (Anderssen \& Milberg 1998). Intraspecific variation in the level of seed dormancy is common among Brazilian species (Lacerda et al., 2004; Silveira et al. 2012), and the question posed is no longer whether a species is dormant or not. Rather, we should be asking ourselves if individuals or populations present dormant seeds and what are the conditions that have favoured the evolution of dormancy in these demes. Failure to identify the correct dormancy-breaking methods or germination stimulants represents a waste of time and money (Thompson \& Ooi 2010), which Brazilian science cannot afford. In addition, misunderstandings can have profound implications for agricultural systems (Benech-Arnold et al. 2000), as well as for the conservation and management of biodiversity.

A better understanding of the biogeographical and phylogenetic distribution of seed dormancy across vegetation types (Baskin \& Baskin, 2005) is key for addressing the ecology and evolution of seed dormancy. However, a global assessment of seed dormancy will only be possible if comparisons can be made across studies indexed for databases. To improve communication, a fostered debate on the discussed paradigms should be sought among seed scientists. I hope the "seeds" sown here can germinate and future studies will incorporate some of the recommendations made here.

This essay provides a direct protocol to which corrections and improvements are encouraged and welcome (see Hilhorst 2011 for further details). No argument is made here on which definitions of seed dormancy or classification systems should be followed. Instead, it is argued that standardizing seed dormancy research is mandatory. In times when the scientific production of Brazil is growing at an astonishing pace and gaining international attention (Regalado 2010), it is vital to establish effective communication between Brazilian and foreigners seed scientists. discussions promoting improvements in the design and interpretation of germination experiments are expected to result in higher quality data on seed germination of our native flora. If that occurs, the goal of this paper would have been achieved.

\section{Acknowledgments}

This work received financial support from the Brazilian Coordenação de Aperfeiçoamento de Pessoal de Nível Superior (CAPES, Office for the Advancement of Higher Education) and Conselho Nacional de Desenvolvimento Científico e Tecnológico (CNPq, National Council for Scientific and Technological Development), as well as from the Fundação de Amparo à Pesquisa do Estado de Minas Gerais (FAPEMIG, Foundation for the Support of Research in the state of Minas Gerais). I also thank JP Lemos-Filho, LC Martins and LV Modolo for their advice and the editor of the journal for the opportunity to discuss the ideas presented here. This paper benefited from the comments of two anonymous reviewers. I wish to thank all Brazilian seed scientists who continuously contribute to a better understanding of the ecology and evolution of seed dormancy and germination of our native flora.

\section{References}

Anderssen, L. \& Milberg, P. 1998. Variation in seed dormancy among mother plants, populations and years of seed collection. Seed Science Research 8: 29-38.

Baskin, C.C. \& Baskin, J.M. 2004. A classification system for seed dormancy. Seed Science Research 14: 1-16

Baskin, C.C., Thompson K. \& Baskin, J.M. 2006. Mistakes in germination ecology and how to avoid them. Seed Science Research 16: 165-168.

Baskin, J.M. \& Baskin, C.C. 2005. Classification, biogeography and phylogenetic relationships of seed dormancy. Pp. 517-544 In: Smith, R.D., Dickie, J.B., Linington, S.H., Pritchard, H.W. \& Probert R. J. (Eds.). Seed conservation: turning science into practice. London, The Royal Botanic Gardens.

Benech-Arnold R.L.; Sanchez, R.A.; Forcella, F.; Kruk, B.C.; \& Ghersa. C.M. 2000. Environmental control of dormancy in weed seed banks in soil. Field Crops Research 67: 105-122.

Brasil 2009. Regras para análises de sementes. MAPA, Brasília.

Cardoso, V.J.M. 2004. Dormência: estabelecimento do processo. Pp. 95 108. In: Ferreira, A.G. \& Borghetti, F. (Ed.). Germinação: do básico ao aplicado. Porto Alegre, Artmed.

Delouche. J.C.; Still, T.W.; Raspet, M. \& Lienhard, M. 1962. The tetrazolium test for seed viability. Mississippi, Agr. Exp. Sta. Tech. Bull.

Finch-Savage, W.E. \& Footit, S. 2012. To germinate or not to germinate: a question of dormancy relief not germination stimulation. Seed Science Research 22: 243-248. 
Finch-Savage, W.E. \& Leubner-Metzger, G. 2006. Seed dormancy and the control of germination. New Phytologist 171: 501-523.

Finkelstein, R.; Reeves, W.; Ariizumi, T. \& Steber, C. 2008. Molecular aspects of seed dormancy. Annual Review of Plant Biology 59: 387-415.

Forzza, R.C.; Baumgratz, J.F.A.; Bicudo, C.E.M.; Canhos, D.A.L.; Carvalho Jr., A.A.; Coelho, M.A.N.; Costa, A.F.; Costa, D.P.; Hopkins, M.G.; Leitman, P.M.; Lohmann, L.G.; Lughadha, E.N.; Maia, L.C.; Martinelli, G.; Menezes, M.; Morim, M.P.; Peixoto, A.L.; Pirani, J.R.; Prado, J.; Queiroz, L.P.; Souza, S.; Souza, V.C.; Stehmann, J.R.; Sylvestre, L.S.; Walter, B.M.T. \& Zappi, D.C. 2012. New Brazilian floristic list highlights conservation challenges. Bioscience 62: 39-45.

Galastri, N.A. \& Oliveira, D.M.T. 2010. Morfoanatomia e ontogênese do fruto e semente de Vernonia platensis (Spreng.) Less. (Asteraceae). Acta Botanica Brasilica 24: 73-83.

Gupta, R.D. \& Murty, Y.S. 1985. Studies on seed storage and viability in some weed seeds of family Asteraceae. Seed Res. 13: 68-76.

Hilhorst, H.W.M. 2011. Standardizing Seed Dormancy Research. Pp. 43-52. In: Kermode A.R. (Ed.). Seed dormancy: methods and protocols. Springer.

Lacerda, D.R.; Lemos-Filho, J.P.; Goulart, M.F.; Ribeiro, R.A. \& Lovato, M.B. 2004. Seed-dormancy variation in natural populations of two tropical leguminous tree species: Senna multijuga (Caesalpinoideae) and Plathymenia reticulata (Mimosoideae). Seed Science Research 14: 127-135.

Le Stradic, S. 2012. Composition, phenology and restoration of campo rupestre mountain grasslands - Brazil. $\mathrm{PhD}$ Thesis. Universidade Federal de Minas Gerais.

Linkies, A.; Graeber, K.; Knight, C. \& Leubner-Metzger, G. 2010. The evolution of seeds. New Phytologist 186: 817-831.
McNair, J.N.; Sunkara, A. \& Frobish, D. 2012. How to analyse seed germination data using statistical time-to-event analysis: non-parametric and semi-parametric methods. Seed Science Research 22: 77-95.

Piña-Rodrigues, F.C.M.; Figliola, M.B. \& Peixoto, M.C. 2004. Testes de qualidade. Pp. 283-298. In: Ferreira, A.G. \& Borghetti, F. (Ed.). Germinação: do básico ao aplicado. Porto Alegre, Artmed.

Ranal, M.A. \& Santana, D.G. 2006. How and why to measure the germination process? Revista Brasileira de Botânica 29: 1-11.

Regalado, A. 2010. Brazilian science: riding a gusher. Science 330: 1306-1312.

Santana, D.G.; Wielewicki, A.P. \& Salomão, A.A. 2012. Validation of quality tests for forest species seeds. Seed Science Research 22(Supplement): S74-S79.

Silva, E.A.A.; Melo, D.L.B.; Davide, A.C.; Faria, J.M.R. \& Hilhorst, H.W.M. 2007. Germination ecophysiology of Annona crassiflora Mart. Annals of Botany 99: 823-830.

Silveira, F.A.O.; Ribeiro, R.C.; Oliveira, D.M.T.; Fernandes, G.W. \& LemosFilho, J.P. 2012. Evolution of physiological dormancy multiple times in Melastomataceae from Neotropical montane vegetation. Seed Science Research 22: 37-44

Simão, E.A.T.; Nakamura \& Takaki, M. 2007. Época de colheita e capacidade germinativa de sementes de Tibouchina mutabilis (Vell.) Cogn. (Melastomataceae). Biota Neotropica 7: 67-73.

Thompson, K. \& Ooi, M.K.J. 2010. To germinate or not to germinate: more than just a question of dormancy. Seed Science Research 20: 209-211.

Velten, S.B. \& Garcia, Q.S. 2005. Efeitos da luz e da temperatura na germinação de Eremanthus (Asteraceae), ocorrentes na Serra do Cipó, MG, Brasil. Acta Botanica Brasilica 19: 755-763.

Vleeshouwers, L.M., Bouwmeester, H.J. \& Karssen, C.M. 1995. Redefining seed dormancy: an attempt to integrate physiology and ecology. Journal of Ecology 83: 1031-1037. 